\title{
Research on method of remote sensing data quality contrast among different quantization levels
}

\author{
Lidong Guo, Guoqing Li \\ Key Laboratory of Digital Earth \\ Institute of Remote Sensing and Digital Earth, Chinese \\ Academy of Sciences (CAS) \\ Beijing, China
}

\author{
Lidong Guo \\ University of Chinese Academy of Sciences \\ (UCAS) \\ Beijing, China
}

\begin{abstract}
Quantization must be taken in the process of data digitization and storage. Remote sensing data use different quantization levels in the process of gathering and storage. Remote sensing data is always compared with other data to decide whether its quality is good or bad, using many quality indexes. But these quality indexes cannot be used directly when the data is compared with other data using different quantization levels. This paper analyses how data quality indexes are affected when quantization level changes, then tests and verifies the result using some experimental data, and puts forward a method remote sensing data quality contrast between different quantization levels based on conversion of quantization level.
\end{abstract}

Key words-Remote sensing data quality, quantization level, quality contrast

\section{INTRODUCTION}

Evaluation methods of the remote sensing data quality are generally classified into two types: the subjective evaluation and the objective evaluation. Metrics on objective evaluation include information entropy, radiometric accuracy, signal-tonoise ratio (SNR), resolution and modulation transfer function (MTF) and so on. Remote sensing data are stored in different bit lengths to obtain different quantization levels, typical cases are 8-bit or 16-digit storage. According to [3], different quantization levels have different impacts on SNR, MTF and the dynamic range of data, thus metrics on objective evaluation cannot be directly put to comparison among different quantization levels. In this paper, effects of quantization levels on objective metrics are discussed, and a method is proposed to compare the data quality on the basis of conversion of quantization levels.

\section{REMOTE SENSING DATA QUALITY OBJECTIVE EVALUATION INDEXES}

\section{A Information quantity}

Information quantity can show richness of image information. It is always expressed by information entropy. Information entropy is defined in many ways, such as shannonwiener entropy, conditional entropy, square entropy, cubic entropy, and so on. Among these definitions, shannon-wiener entropy is most frequently used, and its formula is shown as follows according to [4].

$$
H=-\sum_{i=1}^{M}\left(P_{i} \log \mathrm{P}_{i}\right)
$$

In this formula, $\mathrm{i}$ stands for image's grey value, and $\mathrm{P}_{-} \mathrm{i}$ stands for the probability of grey value $i$.

\section{B Accuracy of radiation}

This index includes six parameters according to [2]: mean value, variance, skewness, gradient, edge radiation distortion and gain adjustment distortion. All these parameters reflect image radiation condition, and their calculation method is showed in table 1 .

Table 1 Six parameters of accuracy of radiation

\begin{tabular}{|c|c|c|}
\hline parameters & meaning & Calculation formula \\
\hline Mean value & $\begin{array}{c}\text { Reflects general } \\
\text { radiation condition of } \\
\text { image }\end{array}$ & $\mathrm{M}=\sum \mathrm{i} \times \mathrm{p}(\mathrm{i})$ \\
\hline Variance & $\begin{array}{c}\text { Reflects richness of } \\
\text { image information }\end{array}$ & $\mathrm{S}=\sum(\mathrm{i}-\mathrm{m})^{3} \mathrm{p}(\mathrm{i}) / \mathrm{d}^{3}$ \\
\hline Skewness & $\begin{array}{c}\text { Reflects the degree of } \\
\text { how distribution shape } \\
\text { is deviated from } \\
\text { symmetrical shape } \\
\text { around mean value in } \\
\text { image histogram. }\end{array}$ & $\begin{array}{c}\text { Reflects gradient of } \\
\text { image histogram. }\end{array}$ \\
\hline Gradient & $\begin{array}{c}\text { Reflects radiation } \\
\text { irregularity degree in } \\
\text { row direction }\end{array}$ & $\begin{array}{c}\text { Mean value and variance } \\
\text { of mean value vector in } \\
\text { row direction }\end{array}$ \\
\hline Edge radiation \\
distortion
\end{tabular}

Note: The i stands for image's grey value, and $P_{i}$ stands for the probability of grey value $\mathrm{i}$.

\section{Definition}

The definition reflects acuity of image edge details changes. Around the edge of surface feature in image, the faster grey value changes as location changes, the more clear details of edge is and the higher resolution is. It's commonly calculated using point sharpness algorithm[2]. This index is calculated using the following formula: 


$$
\mathrm{EAV}=\frac{\sum_{\mathrm{i}=1}^{\mathrm{M} \times \mathrm{N}} \sum_{\mathrm{a}=1}^{8}\left|\frac{\mathrm{df}}{\mathrm{dx}}\right|}{\mathrm{M} \times \mathrm{N}}
$$

In the formula, EAV stands for this index, $\mathrm{M}$ and $\mathrm{N}$ stand for row amount and column amount, "df" stands for how much grey value changes, "dx" is distance increment between two pixels. "a" is the number of pixel around pixel i.

\section{$D$ Signal to noise ration(SNR)}

Sensors' SNRs are accessible from the SNRs of imageries. Currently, SNR of remote sensing images are mainly assessed by variance, geographic statistics, local variance, decorrelation method, or neural networks.

SNR of an image is defined as the power spectrum ratio between signal and noise. However, the power spectrum is difficult to be computed, because signal and noise are unknown subsets of the observed data and the restoration process is an illness problem. The variance method was then proposed to use variance ratio of signal and noise to approximate the SNR, which selects a large and uniform area of images and calculates the mean value and standard variance.

The Geographic statistics method found that the DN (digital number) value of ground pixels demonstrate some selfcorrelation with the change of distances, which showed a certain continuity and relevance of the land surface parameters. This to some extent reflects the spatial structure characteristics of remote sensing metrics. The Geographic statistics method then utilizes the changes of pixels correlation in the spatial domain to measure the power of the noise.

Variance method is not flexible in that it needs manually selected uniform regions, so is improved by the local variance method, which divides an image into many $4 \times 4$ or $8 \times 8$ blocks. Each block is assumed to be uniform and calculated to get the mean value and standard variance, and the latter is an approximation of the noise. After all the blocks are calculated, arrange of the largest mode is selected according to all the standard variances, and its mean standard variance is set as the noise value of the whole image. This method demonstrates good assessment on the plain images. To achieve a reliable result, the uniformity of the image needs to be evaluated before the local variance method is used.

The local variance method is improved from variance method. How local variance method is calculated is shown in [1]. According to comparison among different methods by Bo Zhu(2010) and experimental result of each method according to [5], local variance method performances well in calculation speed, reliability, correctness and applicability.

\section{HOW QUANTIZATION LEVEL CHANGING AFFECTS QUALITY INDEX}

We assume that quantization level of data $\mathrm{A}$ is $\mathrm{a}$, and quantization level of data $B$ is $b$, and $a<b$. We also assume that both grey value is integer. So if they are transformed to each other, their grey value of $\mathrm{B}$ is $2^{\mathrm{b}-\mathrm{a}}$ times of that of $\mathrm{A}$, but quality indexes of one is not that times of that of the other. Here we analysis the relationship of quality indexes between A and $\mathrm{B}$ when transformed with each other from the perspective of qualitative analysis in the following part.

\section{A Information quantity}

$\mathrm{H}_{\mathrm{A}}$ stands for information entropy of data $\mathrm{A}$, and $\mathrm{H}_{\mathrm{B}}$ stands for that of $\mathrm{B}$. When $\mathrm{B}$ is transformed to $\mathrm{A}$, quantization level decreases, data richness must also decreases. So $\mathrm{H}_{\mathrm{A}}<\mathrm{H}_{B}$; When $\mathrm{A}$ is transformed to $\mathrm{B}$, quantization level will not change. So $\mathrm{H}_{\mathrm{A}}=\mathrm{H}_{\mathrm{B}}$ 。

\section{B Radiation accuracy}

a) mean value. $M$ stands for mean value of data. When $B$ is transformed to A, grey value of B will be divided by $2^{\mathrm{b}-\mathrm{a}}$. Some value may be decimal and when it is transformed to integer the value will be smaller. So $\mathrm{M}_{\mathrm{A}}<\mathrm{M}_{\mathrm{B}} / 2^{b-\mathrm{a}}$. When $\mathrm{A}$ is transformed to $\mathrm{B}$, grey value of $A$ will be multiplied by $2^{\mathrm{b}-\mathrm{a}}$. No value will be decimal, and value of $\mathrm{B}$ is $2^{\mathrm{b}-\mathrm{a}}$ times of that of $\mathrm{A}$. So $\mathrm{M}_{\mathrm{A}}=\mathrm{M}_{\mathrm{B}} / 2^{b-\mathrm{a}}$.

b) variance. $\mathrm{D}$ stands for variance of data. When $\mathrm{B}$ is transformed to $\mathrm{A}$, quantization level decreases, value of $\mathrm{A}$ will be smaller than value of $\mathrm{B}$ divided by $2^{\mathrm{b}-\mathrm{a}}$. In the formula whether the value of (i-m) decreases or increases cannot be confirmed. $D_{A} \neq D_{B} / 2^{2(b-a)}$. When $\mathrm{A}$ is transformed to $\mathrm{B}$, value of $\mathrm{A}$ is equal to value of $\mathrm{B}$ divided by $2^{\mathrm{b}-\mathrm{a}}$. So $\mathrm{D}_{\mathrm{A}}=\mathrm{D}_{\mathrm{B}} / 2^{2(b-a)}$.

c) skweness. $S_{A}$ stands for skewness of data. As it's discussed before, when $\mathrm{B}$ is transformed to data $\mathrm{A}$, grey value of $\mathrm{A}$ is smaller than that of $\mathrm{B}$ divided by $2^{\mathrm{b}-\mathrm{a}}$, from the formula we can see relationship between $S_{A}$ and $S_{B}$ cannot be confirmed. $S_{A} \neq S_{A} \times$ $2^{3(b-a)}$. Otherwise when $\mathrm{A}$ is transformed to $\mathrm{B}, \mathrm{S}_{\mathrm{A}}=$ $\mathrm{S}_{\mathrm{A}} \times 2^{3(b-a)}$.

d) gradient. $K_{A}$ stands for gradient of data. When $B$ is transformed to $\mathrm{A}$, the relationship between $\mathrm{K}_{\mathrm{A}}$ and $\mathrm{K}_{\mathrm{B}} \times 2^{4(b-\mathrm{a})}$ cannot be confirmed. $\mathrm{K}_{\mathrm{A}} \neq \mathrm{K}_{\mathrm{B}} \times 2^{4(b-\mathrm{a})}$, when $\mathrm{A}$ is transformed to $\mathrm{B}, \mathrm{K}_{\mathrm{A}}=\mathrm{K}_{\mathrm{B}} \times 2^{4(b-a)}$.

e) radiation distortion. Edge radiation distortion is expressed by mean value and variance of mean value vector in row direction. $\mathrm{Rd}$ stands for variance of mean value vector in row direction. $\mathrm{Rd}$ is analyzed as that of variance. Gain radiation distortion is expressed by mean value and variance of mean value vector in column direction. Pd stands for variance of mean value vector in column direction. Pd is analyzed as that of variance.

\section{Signal to noise ration(SNR)}

For the benefits of local variance method, here we choose it to calculated SNR. Ps stands for local standard deviation, $\mathrm{m}$ stands for mean value. So $\mathrm{SNR}=\frac{m}{P S}$. When $\mathrm{B}$ is transformed to $\mathrm{A}, \mathrm{m}$ decreased and Ps cannot be so sure. $S N R_{A} \neq S N R_{B}$. Otherwise, when $\mathrm{A}$ is transformed to $\mathrm{B}$, value $\mathrm{m}$ is multiplied by $2^{\mathrm{b}-\mathrm{a}}$ and Ps is also multiplied by $2^{\mathrm{b}-\mathrm{a}}$, so SNR is not changed. So $S N R_{A}=S N R_{B}$. 


\section{Definition}

Definition is calculated by following formula:

$$
\mathrm{EAV}=\frac{\sum_{\mathrm{i}=1}^{\mathrm{M} \times \mathrm{N}} \sum_{\mathrm{a}=1}^{8}\left|\frac{\mathrm{df}}{\mathrm{dx}}\right|}{\mathrm{M} \times \mathrm{N}}
$$

When data $\mathrm{B}$ is transformed to data $\mathrm{A}, \mathrm{M}$ and $\mathrm{N}$ is not changed. In the formula $\mathrm{df}=\mathrm{a}-\mathrm{i}$. We assume that original value of $\mathrm{a}, \mathrm{i}$ and df in data $\mathrm{B}$ is $\mathrm{Ba}, \mathrm{Bi}$ and Bdf. So

$$
\mathrm{a}<=\mathrm{Ba} / 2^{\mathrm{b}-\mathrm{a}}
$$

$\mathrm{Ba}-\mathrm{a}^{*} 2^{\mathrm{b}-\mathrm{a}}=0$, or 1 .

$$
\mathrm{Bi}-\mathrm{i}^{*} 2^{\mathrm{b}-\mathrm{a}}=0 \text {, or } 1 \text {. }
$$

so $|\mathrm{Bdf}|-|\mathrm{df}| * 2^{\mathrm{b}-\mathrm{a}}=0,1$, or -1

$$
E A V_{B}-E A V_{a} * 2^{\mathrm{b}-\mathrm{a}}=\frac{\sum_{\mathrm{i}=1}^{\mathrm{M} \times \mathrm{N}} \sum_{\mathrm{a}=1}^{8} \frac{\{-1,0,1\}}{\mathrm{dx}}}{\mathrm{M} \times \mathrm{N}}
$$

when $\mathrm{A}$ is transformed to $\mathrm{B}$

$$
E A V_{B}=E A V_{A} * 2^{\mathrm{b}-\mathrm{a}}
$$

\section{EXPERIMENTAL DATA ANALYSIS}

We choose one panchromatic data whose quantization level is 10 , and one panchromatic data whose series is 8 .

a) Firstly, quantization level 10 is transformed to 8, meaning data value ranges from 0 to 1023 is compressed to 0 to 255. Assume that data B has quantization level 10, and data A has quantization level 8. Data quality result of $\mathrm{B}$ and $\mathrm{A}$ is showed in table 1 and table 2 below. From the last column of table 1 , we can see that decreasing quantization level can cause significant effect on information quantity and SNR, less effect on other quality

\begin{tabular}{|c|c|c|c|c|c|}
\hline $\begin{array}{l}\text { Quality } \\
\text { index }\end{array}$ & Data B & Data A & $\begin{array}{c}\text { Multipl } \\
\text { e }\end{array}$ & $\begin{array}{c}\text { A } \\
\text { multiply } \\
\text { by } \\
\text { muliple }\end{array}$ & $\begin{array}{c}\text { Compare } \\
\text { d with } \\
\text { data B } \\
(\%)\end{array}$ \\
\hline $\begin{array}{c}\text { Informatio } \\
\text { n quantity }\end{array}$ & 7.82576 & 5.82136 & null & 5.82136 & 25.61285 \\
\hline $\begin{array}{l}\text { Mean } \\
\text { value }\end{array}$ & 311.288 & 77.4469 & 4 & 309.7876 & 0.481997 \\
\hline Variance & 3742.77 & 234.002 & 16 & 3744.032 & -0.03372 \\
\hline Skewness & $\begin{array}{c}2.64498 \mathrm{e} \\
-006 \\
\end{array}$ & $\begin{array}{c}0.00016911 \\
2 \\
\end{array}$ & $1 / 64$ & $\begin{array}{c}2.6424 \mathrm{e}- \\
006\end{array}$ & 0.097543 \\
\hline Gradient & $\begin{array}{c}1.92513 \mathrm{e} \\
-007 \\
\end{array}$ & $\begin{array}{l}4.92542 \mathrm{e}- \\
005\end{array}$ & $1 / 256$ & $\begin{array}{c}1.92400 \mathrm{e} \\
-007 \\
\end{array}$ & 0.058697 \\
\hline $\begin{array}{c}\text { Edge } \\
\text { radiation } \\
\text { distortion } \\
\text { variance }\end{array}$ & 857.48 & 53.3761 & 16 & 854.0176 & 0.403788 \\
\hline $\begin{array}{c}\text { Gain } \\
\text { adjustment } \\
\text { variance }\end{array}$ & 34.2465 & 2.12648 & 16 & 34.02368 & 0.650636 \\
\hline SNR & 61.2842 & 74.9102 & NULL & 74.9102 & -22.2341 \\
\hline Definition & 26.2378 & 6.57457 & 4 & 26.29828 & -0.23051 \\
\hline
\end{tabular}
indexes. The error of information quantity is more than $25 \%$. The error of SNR is $-22.2341 \%$. The error of other index is little.
Table 1PANCHROMATIC DATA

b) Secondly : quantization level 8 is transformed to 10 , meaning grey value ranging from $0 \sim 255$ is expanded to $0 \sim 1023$. It's done by multiplying each grey value by 4 . The result of each index is showed in table2. From the last

\begin{tabular}{|c|c|c|c|c|c|}
\hline $\begin{array}{l}\text { Quality } \\
\text { index }\end{array}$ & Data B & Data A & $\begin{array}{c}\text { Multipl } \\
\text { e }\end{array}$ & $\begin{array}{c}\text { A } \\
\text { multipl } \\
\text { y by } \\
\text { muliple }\end{array}$ & $\begin{array}{c}\text { Compare } \\
\text { d with B } \\
(\%)\end{array}$ \\
\hline $\begin{array}{c}\text { Informatio } \\
\text { n quantity }\end{array}$ & 7.32058 & 7.32058 & null & 7.32058 & 0 \\
\hline $\begin{array}{l}\text { Mean } \\
\text { value }\end{array}$ & 333.071 & 83.2677 & 4 & $\begin{array}{c}333.070 \\
8\end{array}$ & $6 \mathrm{E}-05$ \\
\hline Variance & 56105 & 3506.56 & 16 & $\begin{array}{c}56104.9 \\
6\end{array}$ & 7.13E-05 \\
\hline Skewness & $\begin{array}{c}7.01471 \mathrm{e} \\
-008\end{array}$ & $\begin{array}{c}4.48941 \mathrm{e} \\
-006\end{array}$ & $1 / 64$ & $\begin{array}{c}7.0147 \mathrm{e} \\
-008\end{array}$ & 0.000143 \\
\hline Gradient & $\begin{array}{c}8.58572 \mathrm{e} \\
-010\end{array}$ & $\begin{array}{c}2.19794 \mathrm{e} \\
-007\end{array}$ & $1 / 256$ & $\begin{array}{c}8.5857 \mathrm{e} \\
-010\end{array}$ & 0.000233 \\
\hline $\begin{array}{c}\text { Edge } \\
\text { radiation } \\
\text { distortion } \\
\text { variance }\end{array}$ & 5923.53 & 369.995 & 16 & 5919.92 & 0.060943 \\
\hline $\begin{array}{c}\text { Gain } \\
\text { adjustment } \\
\text { variance }\end{array}$ & 257.769 & 16.0968 & 16 & $\begin{array}{c}257.548 \\
8\end{array}$ & 0.085425 \\
\hline SNR & 100.375 & 100.893 & 1 & 100.893 & -0.51606 \\
\hline Definition & $\begin{array}{l}185 \\
.782\end{array}$ & 46.4454 & 4 & $\begin{array}{c}185.781 \\
6\end{array}$ & 0.000215 \\
\hline
\end{tabular}
column of table 3 , it can be seen that every index changes very little when quantization level changes from 8 to 10 .

Table 2 QUALITY INDEX VALUE WHEN QUANTIZATION LEVEL CHANGES FROM 8 TO 10

\section{QUALITY CONTRAST METHOD BETWEEN DIFFERENT QUANTIZATION LEVELS}

According to data showed in chapter 4 , we conclude some quality index will change greatly when quantization level decreases, all quality indexes will not change when quantization level increases. So when different quantization 
levels data are compared with each other, data with less quantization level should be transformed to higher level, to make sure both data quantization levels are in the same level. Figure 1 shows the flow chart of quality contrast between different quantization levels.

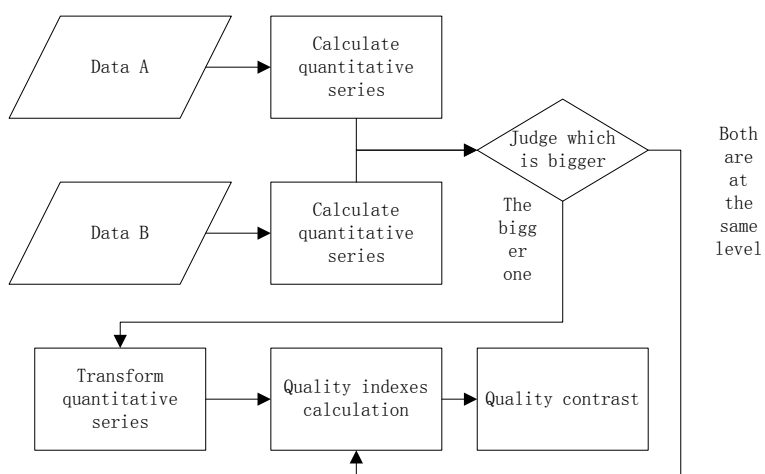

Figure 1 Flow chart of quality contrast between different quantization levels

a) calculate quantization level. It is calculated by investigating a lot of A data's max value, and then decide quantization level. For example, if the max value of A data is between 512 to 1024, then quantization level is 10 .

b) transform quantization level. Firstly, decide which quantization level is bigger. Then transform smaller one to higher one, through multiplying the smaller one's grey value by $2^{\wedge}(b-a)$. If both data quantization levels are the same. There's no need to transform.

c) calculate quality indexes. Calculate each quality index according to what introduced before.

d) quality contrast. Output the result of both data in form of table.

\section{CONCLUSION}

This paper analyses how much quality indexes can be influenced when quantization level is changed. Then test and verify the analysis result by experimenting on experimental data. And the result is that when quantization level decreases, indexes like information quantity decreases greatly, index like SNR is affected, and some other indexes are affected very little. When quantization level is transformed to higher level, quality indexes are not affected.

According to the experimental result, when remote sensing data with different quantization levels are compared with each other in quality, quantization level in lower level should be transformed to higher lever to make sure both data are in the same level. This makes both data comparable, and quality indexes result more reliable.

\section{REFERENCES}

[1] B. Zhu, X. H. Wang, L. L. Tang, C. R. Li. "Review on Methods for SNR Estimation of Optical Remote Sensing Imagery". REMOTE SENSING TECHNOLOGY AND APPLICATION. China, Vol.25, No.2, pp.303-308. Apr.2010.(references)

[2] Y. J. Zhou, Q. J. Tian. "Image Quality Evaluation of EO-1 Hyperion Sensor". GEO-INFORMATION SCIENCE. China, Vol. 10, No.5, pp. 678-683. Oct. 2008.

[3] J. Wang. "Effect of Quantization on Remote Sensing Image Quality". SPACECRAFT RECOVERY \& REMOTE SENSING. Beijing, Vol. 25, No. 4, pp. 46-49. Dec. 2004.(references)

[4] Z. P. Sun, W. C. Xiong, Q. Li, C. Q. Wu, X. M. Liu. "Image Quality Evaluation of HJ-1 Satellite CCD Sensor". INFRARED. China, Vol. 31, No.9, pp.30-36, Sep.2010.

[5] Q. Ran, Y. B. Chi, Z. Y. Wang, Z. C. Chen. "Image-based noise estimation of Beijing-1 small satellite". Journal of Remote Sensing. China, Vol. 13, No. 3, pp. 554-558. 2009. 